\title{
Are Executive Processes Used to Solve Simple Arithmetic Production Tasks
}

S. de Rammelaere and A. Vandierendonck

\section{(2) OpenEdition}

Electronic version

URL: http://journals.openedition.org/cpl/231

DOI: $10.4000 / \mathrm{cpl} .231$

ISSN: $1379-6100$

\section{Publisher}

Centre PsyCLÉ

Printed version

Date of publication: 1 August 2001

\section{Electronic reference}

S. de Rammelaere and A. Vandierendonck, «Are Executive Processes Used to Solve Simple Arithmetic Production Tasks », Current psychology letters [Online], 2001/2, 5| 2001, Online since 16 September 2003, connection on 08 September 2020. URL : http://journals.openedition.org/cpl/231 ; DOI : https:// doi.org/10.4000/cpl.231

This text was automatically generated on 8 September 2020.

(C) All rights reserved 


\section{Are Executive Processes Used to Solve Simple Arithmetic Production Tasks}

S. de Rammelaere and A. Vandierendonck 